\title{
Del lector en Borges: de cruces genéricos e intertextuales
}

\author{
Gerardo Centenera Tapia \\ UNIVERSITÉ PARIS-SORBONNE·gcentenera@gmail.com
}

Doctorando en la Université Paris-Sorbonne. Centra su proyecto en los procedimientos narratológicos y en el escritor argentino Jorge Luis Borges. Sus principales artículos son: "Nueva refutación del viaje en el tiempo. Una lectura de "Utopía de un hombre que está cansado"", "Referencias textuales como criterio genérico en Borges" y "Une lecture de "La secta de los treinta" (estos dos últimos pendientes de publicación).

RECIBIDO: 6 DE JUNIO DE 2013

ACEPTADO: 9 DE NOVIEMBRE DE 2013

Resumen: Exposición de las propuestas teóricas de Borges sobre el género literario. Se plantea la pertinencia de aplicarlas en el análisis de su propia obra. Se discute su validez como herramienta crítica, su influencia en la crítica ulterior y su relación con el conjunto del pensamiento del autor.

Palabras Clave: Borges, género, recepción, hibridez genérica, crítica creativa.

\begin{abstract}
Relation of Borges' theoretical ideas about literary genre. We comtemplate the suitability of applying these ideas in the analysis of Borge's own work; wheter they are valid as a critical tool, its influence in ulterior criticism as well as its relation within the overall thinking of the author.
\end{abstract}

Key Words: Borges, genre, Reception, hybrid genre, creative criticism 
La supuesta arbitrariedad que hace tiempo estamos acostumbrados a asociar a la crítica de Borges parece funcionar aquí. Es posible. Pero también es posible que este funcionandoya otro mecanismo, más importante y significativo.

EMIR RODRÍGUEZ MONEGAL

\section{Introducción}

Este trabajo pretende una aproximación a las ideas teóricas de Jorge Luis Borges sobre el género literario. Su fin es encontrar útiles de trabajo para un estudio ulterior del género en la propia obra de Borges.

Una de las cuestiones inmediatas que suscita el análisis de la obra del escritor argentino es el de su clasificación genérica. Ya en la reseña de la primera aparición de $E l$ jardín de los senderos que se bifurcan, Bioy Casares comienza insinuando la cercanía entre el ensayo y la narrativa como característica fundamental de su autor: "Borges, como los filósofos de Tlön, ha descubierto las posibilidades literarias de la metafísica" (1942: 60).

$\mathrm{Al}$ examinar esta cuestión, es inevitable tener en cuenta las ideas teóricas sobre géneros literarios del propio Borges, de las que ha dejado constancia abundante. La pretensión de esbozar estas ideas nos lleva a necesitar una breve exposición de los problemas derivados de confrontarnos al Borges crítico:

${ }_{\mathrm{C}}$ Es pertinente considerar a Borges como crítico? Muchos de los que han abordado esta cuestión han considerado que no, otorgándole distintos niveles de amateurismo. Así, Rodríguez Monegal:

En realidad, Borges puede ser considerado más que como un crítico literario puro como un crítico practicante, de acuerdo con la útil distinción propuesta por T. S. Eliot. Es decir: como el crítico que estudia aquellos problemas que debe resolver como creador y desdeña (o falsea) los que estorban a su propia invención. Una consideración sumaria de los trabajos críticos de Borges demuestra que a través del análisis de obras ajenas, de problemas generales, de estética, de discusiones filosóficas, Borges busca orientarse en su propio laberinto (1992: 210).

En la misma línea, Arturo Echavarría:

Apreciaciones de obras y escritores, exámenes de recursos poéticos y tentativas de valoración de algunas tradiciones antiguas y modernas [...] podrían bien inclinarnos a calificar a Borges de crítico literario. Sin embargo, sus apreciaciones en tantas ocasiones parciales y fragmentarias [...] sus descuidos, sus intentos conscientes o inconscientes, en otras ocasiones, de atraer la atención del lector más sobre sí mismo que sobre el texto o autor que está comentando, tienden a desvirtuar esa posibilidad (2006: 31-32). 
En estos pasajes se mencionan ya los dos obstáculos generalmente aducidos por aquellos que niegan a Borges la condición de auténtico crítico: su carácter asistemático y misceláneo -por lo que de los Raimundo Lida le llama "crítico fragmentario" (1981: 282) y Prieto "impresionista" (Prieto cit. Gil Guerrero, 2008: 16) - y la supuesta prevalencia de sus intereses como autor, que le vedarían el rigor y objetividad: Prieto le considera como "crítico hedonista" (Prieto cit. Gil Guerrero, 2008: 16). Cuando a Piglia le preguntan su opinión sobre el Borges crítico, le atribuye una "lectura estratégica" (1997: 19): el creador buscaría claves para enfrentarse a su propia obra cuando lee textos ajenos.

En cambio, Herminia Gil Guerrero, en Poética narrativa de Jorge Luis Borges (2008), defiende la faceta crítica borgiana sin necesidad de paliarla con adjetivos para diferenciarla de la crítica académica. Cuesta Abad, por su parte, incluye en su antología de textos fundamentales de la teoría literaria del siglo XX(1995) un artículo extraído de Otras inquisiciones, tras haber dedicado un volumen a analizar con profundidad la faceta interpretativa y hermenéutica de su autor.

Pese a lo discutido de su rigor crítico, a menudo se ha considerado a Borges como precursor de muchas de las corrientes de finales del siglo XX: semiótica, estética de la recepción, postestructuralismo, etc. Así como de tendencias artísticas y tecnológicas. Debemos ser cautos y definir hasta qué punto, al hacer una lectura, inevitablemente desde nuestras propias ideas críticas, le atribuimos hallazgos que pudieran proceder más de la interpretación a posteriori que del texto mismo. Esta prioridad del texto no puede ser pura -podría ser incluso imposible, como sugieren alguna de las corrientes que acabamos de mencionar- pero el hecho de que el mismo Borges pudiera ser inspiración para estas escuelas hace todavía más necesaria tal cautela, para no caer en un improductivo "ya decía Borges que..." y en la petición de principio. Como reconoce José Luis de Diego, en los seminarios de 1988 de la Facultad de Humanidades de La Plata se buscaba la influencia de Borges en Foucalut, Barthes, Kristeva, Jauß y otros, para pronto darse cuenta "de que nuestro trabajo no era en realidad leer autores contemporáneos "a partir de Borges", sino que estábamos recorriendo el camino inverso [...] Borges había resultado no tanto el punto de partida sino más bien el punto de llegada" (1988: 31). Para evitar este problema, intentaremos valorar los hallazgos borgianos en relación con el papel que juegan dentro de su propia concepción literaria. También ilustraremos estos con ejemplos de la tradición de la que proceden esas ideas (a menudo explicitada por el propio Borges) y con ejemplos de hallazgos similares obtenidos por otras personas en fechas similares, con el fin de contextualizar a nuestro autor dentro del clima cultural de su tiempo y relativizar así su papel de precursor a estos datos. 
Por otro lado, la teoría literaria del autor está íntimamente ligada a su concepción estética y filosófica, por lo que, en ocasiones, correremos el riesgo de salir del mero ámbito de la crítica.

\section{Ideas borgianas sobre el concepto de género literario}

Ordenamos los ejemplos según los criterios de clasificación genérica, según sean formales, temáticos o de contenido y los basados en la recepción. También nos detendremos brevemente en los criterios históricos y psicologistas, pero no porque Borges los use, sino porque rebate su pertinencia con argumentos que nos ayudarán a comprender su concepto de género.

Borges utiliza a menudo la palabra "género" en sentido lato o incluso metafórico. Naturalmente, todos esos casos quedan fuera del ámbito que nos hemos propuesto aquí. Por ejemplo: "Estas historias pertenecen al más antiguo de los géneros literarios, la pesadilla" (2005: 548) o "Los sueños, que tejen buena parte de nuestra vida, han sido prolijamente estudiados, desde Artemidoro hasta Jung; no así la pesadilla, el tigre del género" (2005: 533).

Nos centramos únicamente en los textos claramente discursivos -artículos, prólogos, conferencias, entrevistas, etc.- excluyendo los narrativos y los poemas. Si bien en ellos también desarrolla a menudo ideas teóricas, a veces a través de la instancia narrativa o poética, otras a través de personajes cuyas opiniones podemos identificar más o menos con las del autor, etc. Hemos querido evitar la posibilidad de tomar argumentos que pudieran subordinarse a la opinión de un personaje o a otra coyuntura creativa. Naturalmente, abandonamos cualquier ánimo de exhaustividad en las citas, pero sí buscamos que sean representativas del pensamiento de Borges e intentamos tomarlas de un ámbito cronológico amplio, con el fin de ilustrar si se trata de una opinión que atraviesa puntualmente su recorrido, o resulta funcional durante gran parte de su producción. Esto nos llevará, inevitablemente, a cierta prolijidad en las citas.

\subsection{Criterios históricos y psicologistas}

Pese a que en ocasiones escribe semblanzas biográficas de literatos para las revistas con las que colabora -como las "Biografías sintéticas" en El hogar- Borges estima de poca utilidad el análisis de éstas, o de la personalidad o la psicología del autor para la comprensión de las obras, ya que considera a éste "un mero escribiente que no hace más que reescribir en nuevas combinaciones lo que preexiste en las tradiciones de lo escrito" 
(cit. en Blüher, 1986: 456)ำ Respecto a los criterios históricos mantiene la misma postura, por razones similares:

Es muy sabido que a los críticos les interesa menos el arte que la historia del arte (Borges, 1990: 62).

Es sabido que la cronología, que la historia existen; pero son ante todo averiguaciones occidentales. No hay historias de la literatura persa o historias de la filosofía indostánica; tampoco hay historias chinas de la literatura china, porque a la gente no le interesa la sucesión de los hechos. Se piensa que la literatura y la poesía son procesos eternos. Creo que, en lo esencial, tienen razón (Borges, 2005: 279).

Ahora lo perjudica [a Virgilio] nuestra costumbre de leer los libros en función de la historia, no de la estética (Borges, 2005: 560).

Cuando mis estudiantes me pedían bibliografía yo les decía: "no importa la bibliografía; al fin de todo, Shakespeare no supo nada de bibliografía shakesperiana". Johnson no pudo prever los libros que se escribirían sobre él. ¿Por qué no estudian directamente los textos?”" (Borges, 2007: 306).

Como vemos, la misma idea, expresada de maneras diferentes, vuelve a través de los decenios. En unas ocasiones insiste en ella ironizando sobre el hecho de que no sepamos nada sobre autores de grandes obras clásicas; ni siquiera si existieron realmente: "el caso de Esopo -o de los griegos que llamamos Esopo-" (Borges y Ferrari, 2005: 161) y "si es que hubo alguien que se llamó Homero" (Borges, 2011: 696). Otras, exagera o hace notar la banalidad de la vida de autores clásicos: "En el autor de Martín Fierro se ha repetido, mutatis mutandis, la paradoja de Cervantes y de Shakespeare; la del hombre inadvertido y común que deja una obra que las generaciones venideras no querrán olvidar" (2005: 92). En "El idioma analítico de John Wilkins" señala el contraste entre lo trivial de las "meras circunstancias biográficas" consignadas en la entrada de la Encyclopaedia Britannica sobre este autor y lo brillante de su obra.

Aplica un recurso similar a la cronología: "At the end of the eighteenth or the beginning of the beginning of the ninenteenth century, let's say (we need hardly go into a discussion of dates)" (Borges, 2000: 50)² o también: "Dios te libre, lector, de prólogos

1La cita procede originalmente de Valérie, traducida por Borges, que se la apropia. Citada en Blüher, Karl Alfred. "La crítica literaria en Valérie y Borges" Revista Iberoamericana 135-136 (1986): 456 .

2En la misma colección de conferencias, en la página 114, regresa a la misma idea: "I think the ancient idea -that we might allow perfection to art without taking into account the dates- was a braver one". 
largos. La cita es de Quevedo, que, para no cometer un anacronismo que hubiera sido descubierto a la larga, no leyó nunca los de Shaw" (2002b:11).

No suele, por tanto, utilizar este tipo de criterios para clasificar géneros. Existe, no obstante, alguna excepción: se aproxima de alguna manera en "De las alegorías a las novelas" (Borges, 1995c: 153-156). Si bien, más que propiamente histórico, el criterio para diferenciar estos dos géneros es filosófico: considera a las alegorías de estirpe platónicorealista, mientras que las novelas serían su equivalente en la estirpe aristotélico-nominalista; la imposición de este modelo frente al anterior, dice, "llevó algunos siglos". Data el cambio concretamente en 1382. Esta opinión tiene implicaciones sobre las que volveremos.

\subsection{Criterios formales y temáticos o de contenido}

Para mayor sencillez en la exposición, nos fijamos en la aplicación de estos criterios a dos géneros muy codificados: el relato policial y el fantástico. Por otro lado, se trata de dos géneros asiduamente visitados tanto por el Borges creador como por el teórico y marcan una parte importante de su producción.

Sobre el uso de criterios formales en el análisis literario, es conveniente recordar que para que el formalismo ruso fuera conocido internacionalmente hubo que esperar a que sus textos fueran traducidos a las lenguas de cultura occidentales. El 4 de febrero de 1938 Borges publica estas líneas:

El cuento de hadas europeo (y el árabe) son del todo convencionales. Una ley ternaria los rige: hay dos hermanas envidiosas y una hermanita buena, hay tres hijos de rey, hay tres cuervos, hay una adivinanza que descifra el tercer adivinador. El cuento occidental es una especie de artefacto simétrico, dividido en compartimentos. Es de una simetría perfecta (Borges, 1990: 204).

La obra capital de Vladimir Propp, Morfología del cuento(1965 y 1970), si bien fue publicada originalmente en 1928, no se tradujo al inglés hasta 1958 y al francés siete años más tarde.

Pero si Propp descubrió los mecanismos de los cuentos tradicionales gracias a su estructura rígida y convencional, Borges había observado otro tanto en los relatos policiales.

La primera y más detallada ocasión en la que Borges explica los rasgos definitorios de este género "acaso más artificial de cuantos la literatura comprende" (Borges, 1990: 323)es en el número de julio de 1935 de Sur:

A) Un límite discrecional de personajes. La infracción temeraria de esa ley tiene la culpa de la confusión y el hastío de todos los films policiales [...]

B) Declaración de todos los términos del problema. [...] En los cuentos honestos, el criminal es una de las personas que figuran desde el principio. 
C) Avara economía en los medios. [...]

D) Primacía del cómo sobre el quién. [...]

E) El pudor de la muerte. [...] pero esas pompas de la muerte no caben en la narración policial, cuyas musas glaciales son la higiene, la falacia y el orden.

F) Necesidad y maravilla en la solución. Lo primero establece que el problema debe ser un problema determinado, apto para una sola respuesta. Lo segundo requiere que esa respuesta maraville al lector - sin apelar a lo sobrenatural, claro está, cuyo manejo en este género de ficciones es una languidez y una felonía. También están prohibidos el hipnotismo, las alucinaciones telepáticas, los presagios, los elixires de operación desconocida, los ingeniosos trucos seudocientíficos y los talismanes. [...] (Borges, 1999a: 127-129).

También en este caso, otros autores llegaban a conclusiones similares en esos mismos años y publicaban sus listas de reglas para el género: en 1929, en la introducción de TheBest Detective Stories of 1928-29, Roland Knox publica sus "Diez mandamientos del relato policial". Por su parte, S.S. Van Dine, que a diferencia de Knox no era teólogo, redactó una lista de veinte mandamientos, aparecida originalmente en American Magazine, $1928^{3}$.

Como ellos, el tono del ejemplo de Borges que acabamos de ver era claramente prescriptivo: aunque fiel al fondo, cuando revisita estas ideas posteriormente, éste se va dulcificando poco a poco hacia lo descriptivo. Veamos algunos fragmentos en orden cronológico:

Puedo afirmar que cumple con los primeros requisitos del género [Half-Way House, de Ellery Queen]: declaración de todos los términos del problema, economía de personajes y de recursos, primacía del cómo sobre el quién, solución necesaria y maravillosa, pero no sobrenatural (Borges, 1990: 40).

En Inglaterra el género policial es como un ajedrez gobernado por leyes inevitables. El escritor no debe escamotear ninguno de los términos del problema. El misterioso criminal, por ejemplo, tiene que ser una de las personas que figuran desde el principio (Borges, 1990: 237).

Las ficciones de índole policial [...] refieren hechos misteriosos que luego justifica e ilustra un hecho razonable (Borges, 1999b: 89-90).

Este relato ["Los crímenes de la Rue Morgue"] fija las leyes esenciales del género: el crimen enigmático y, a primera vista, insoluble, el investigador sedentario que lo descifra por medio de la imaginación y de la lógica, el caso

3Tanto los mandamientos de Knox como los de Van Dine se recopilan y analizan en Haycraft, Howard (1941). Murder for Pleasure. New York City: D. Appleton-Century Company: 223-258. 
referido por un amigo impersonal, y un tanto borroso, del investigador (Borges, 2005: 52).

Este volumen [Gilbert Ketth Chesterton: La Cruz Azul Y Otros Cuentos] consta de una serie de cuentos que simulan ser policiales y que son mucho más. Cada uno de ellos nos propone un enigma que, a primera vista, es indescifrable. Se sugiere después una solución no menos mágica que atroz, y se arriba por fin a la verdad, que procura ser razonable (Borges, 2005: 483).

En sus últimos años declaró alguna vez haber perdido el interés por el género, pero aún entonces reconocía que la fuente de su interés era lo codificado de su estructura:

Frente a una literatura caótica, la novela policial me atraía porque era un modo de defender el orden, de buscar formas clásicas, de valorizar la forma. Para cualquier persona que esté encandilada por el género policial, todo lo otro le resulta más bien informe. Luego descubro que ese rigor y esa coherencia pueden reducirse a un pequeño grupo de artificios; comienzo a sentir que Stevenson tiene razón cuando dice que la novela policial deja la impresión de algo ingenioso pero sin vida. Y entonces me doy cuenta de que los autores que más me atraen no son estrictamente policiales: Wilkie Collins -amigo de Dickens y quizá el primero que usó el procedimiento de que una historia fuera contada por las personas de la fábula- (Lafforgue y B. Rivera, 1996: 47-48).

La economía de medios y la brevedad son características comunes con el relato fantástico, de manera que lo que veremos sobre esos particulares a continuación, podríamos aplicarlo también al policial.

Las dos palabras que forman la expresión "relato fantástico" aluden, respectivamente, a una característica formal -narración breve- y a otra de contenido; la aparición de una serie de motivos considerados fantásticos. En una conferencia de 1944 Borges (cit. por Monegal, 1976: 186) los resume a cuatro posibilidades:

A) La obra de arte dentro de la misma obra

B) La contaminación de la realidad por el sueño

C) El viaje en el tiempo

D) El doble

La lista llama la atención por su brevedad: está directamente relacionada con la idea borgiana que considera las novedades como meras variaciones de unos pocos temas 
seculares4: "quien busca novedades las hallará con más facilidad en los antiguos" (Borges, 1995c: 71). Efectivamente, en otra conferencia, veintitrés años más tarde, se expresaba en términos semejantes:

De un lado, tenemos la literatura realista, la literatura que trata de situaciones más o menos comunes en la humanidad, y del otro la literatura fantástica, que no tiene otro límite que las posibilidades de la imaginación. Uno diría también que la literatura fantástica tiene que ser mucho más rica que la realista ya que no está ceñida a lo cotidiano, sino que debe y puede aventurarse a toda suerte de aventuras. Sin embargo, al cabo de muchos años de ser lector y a veces autor de libros fantásticos he comprobado que los temas de la literatura fantástica no son ilimitados; son unos pocos (Borges, 1967: 5).

En cambio, cuando desarrolla el asunto, la enumeración no coincide exactamente con la que acabamos de ver:
A) La transformación
B) La confusión de lo onírico con lo real
C) El hombre invisible
D) Juegos con el tiempo
E) La presencia de seres sobrenaturales entre los hombres
F) El doble
G) La idea de las acciones paralelas

Es ligeramente más prolija, pero prevalece la idea de lo limitado de los temas posibles: "Yo no sé si podríamos ir mucho más lejos; no sé si hay muchos otros temas fantásticos. Sospecho que no, sospecho que podemos reducir las maravillas de los cuentos fantásticos a éstas que he bosquejado" (Borges, 1967: 16).

Por lo tanto, las dos características que definen al relato fantástico tienen en común la economía de medios y definen este género frente a la novela, pues como leemos en la entrevista publicada en Cambio de Palabras. "En las novelas hay mucho de inservible.

\footnotetext{
4El principio de combinación de un número muy limitado de temas seculares lo aplica Borges a todos los géneros; por ejemplo, a propósito de la poesía, en su conferencia "A Poet's Creed": "I suppose I haveleftoutsome quite commonpatterns. We have so far taken up eyes and stars, women and flowers, time and rivers, life and dream, death and sleeping, fire and battles. Had we time and learning enough, we might find a half a dozen other patterns, and perhaps those might give us most of the metaphors in literature"'(Borges, 2000: 33).
} 
Tienen que ponerle paisajes, digresiones, intervienen las opiniones del autor" (Hildebrant, 2008: 147-155).

Si a una estructura narrativa pueden convenirle diversos rasgos circunstanciales, más o menos intercambiables, considera el abuso de éstos como una característica propia y definitoria de la novela: algunos consideran EI Qüjote la primera novela moderna, otros Robinson Crusoe. El autor argentino decide la cuestión sobre ese criterio: "Si no me engaño, el hallazgo esencial de Daniel Defoe (1660-1731) fue la invención de rasgos circunstanciales, casi ignorada por la literatura anterior. Lo tardío de ese descubrimiento es notable; que yo recuerde, no llueve una sola vez en todo el Quijote" (Borges, 2005: 534).

Otra característica que opone el cuento a la novela es lo que Borges llama la "simulación psicológica". Desarrolla el asunto fundamentalmente en el prólogo de La invención de Morel.

La novela característica, "psicológica", propende a ser informe. Los rusos y los discípulos de los rusos han demostrado hasta el hastío que nadie es imposible: suicidas por felicidad, asesinos por benevolencia, personas que se adoran hasta el punto de separarse para siempre, delatores por fervor o por humildad... Esa libertad plena acaba por equivaler al pleno desorden. Por otra parte, la novela "psicológica" quiere ser también novela "realista": prefiere que olvidemos su carácter de artificio verbal y hace de toda vana precisión (o de toda lánguida vaguedad) un nuevo toque verosímil. Hay páginas, hay capítulos de Marcel Proust que son inaceptables como invenciones: a los que, sin saberlo, nos resignamos como a lo insípido y ocioso de cada día. La novela de aventuras, en cambio, no se propone como una transcripción de la realidad: es un objeto artificial que no sufre ninguna parte injustificada. El temor de incurrir en la mera variedad sucesiva del Asno de Oro, de los siete viajes de Simbad o del Quijote, le impone un riguroso argumento (Borges, 1999b: 89-90).

Así como en el ensayo "El arte narrativo y la magia":

He distinguido dos procesos causales: el natural, que es el resultado incesante de incontrolables e infinitas operaciones; el mágico, donde profetizan los pormenores, lúcido y limitado. En la novela, pienso que la única posible honradez está con el segundo. Quede el primero para la simulación psicológica (Borges, 1995a: 79).

De estos párrafos ricos y complejos queremos destacar un elemento en particular: la estructura propia de la narración fantástica impone mayores restricciones que la de la novela realista, reduce las causalidades posibles: una vez más, se impone un criterio económico que hemos mencionado a propósito del relato policial. Por otro lado, el carácter codificado de estos dos géneros los aproxima al clasicismo. 


\subsection{Criterios de la recepción}

Hemos visto hasta ahora el poco interés que Borges otorga a los detalles biográficos y cronológicos para considerar una obra literaria. Otro tanto ocurre con la originalidad, ya que la labor literaria no es más que la combinación y revisión de temas seculares. Ambos factores nos llevan a otra idea recurrente en su obra: la importancia mínima del autor, reducido a un papel de "mero escribiente". Podemos citar muchos pasajes donde formula esta negación del ego casi budista:

Hacia 1938, Paul Valéry escribió: "La Historia de la literatura no debería ser la historia de los autores y de los accidentes de su carrera o de la carrera de sus obras sino la Historia del Espíritu como productor o consumidor de literatura. Esa historia podría llevarse a término sin mencionar un solo escritor". No era la primera vez que el Espíritu formulaba esa observación; en 1844, en el pueblo de Concord, otro de sus amanuenses había anotado: "Diríase que una sola persona ha redactado cuantos libros hay en el mundo; tal unidad central hay en ellos que es innegable que son obra de un solo caballero omnisciente" (Emerson: Essays, 2, VIII). Veinte años antes, Shelley dictaminó que todos los poemas del pasado, del presente y del porvenir, son episodios o fragmentos de un solo poema infinito, erigido por todos los poetas del orbe (A Defence of Poetry, 1821) (1995c: 17).

Un ejemplo más: "A Bernard Shaw le preguntaron una vez si creía que el Espíritu Santo había escrito la Biblia. Y contestó: "Todo libro que vale la pena de ser releído ha sido escrito por el Espíritu". Es decir, un libro tiene que ir más allá de la intención de su autor" (Borges, 2005: 179).

Por ello, los mayores logros de una obra no son controlados por el autor:

Sus libros más famosos [los de Giovanni Papini] [...] fueron escritos para ser obras maestras, género que requiere cierta inocencia de parte del autor (2005: $503)$.

Kipling observa que a un escritor le está permitido urdir fábulas, pero le está vedado saber cuál es la moraleja (2005: 549).

Virgilio se propuso una obra maestra; curiosamente la logró. Digo curiosamente; las obras maestras suelen ser hijas del azar o de la negligencia (2005: 560).

Claro, si el Quijote fuera simplemente una sátira contra los libros de caballería no sería el Quijote. Si al final, cuando termina la obra, el autor piensa que hizo lo que se propuso, la obra no vale nada [...]. Se me ocurre algo. Supongamos que Esopo existió y que escribió sus fábulas. Pero posiblemente le divertía más la idea de animales que hablan como hombrecitos que las moralejas. Esas moralejas 
se agregaron después [...] Solamente cuando una obra no vale es cuando cumple los propósitos del autor... (2002a: 25-28).

Una de las condiciones indispensables para redactar un libro famoso, un libro que las generaciones futuras no se resignarán a dejar morir, puede ser el no proponérselo (Borges, 1962).

La combinatoria es un tema habitual en sus relatos -quizá el ejemplo más evidente sea "La biblioteca de Babel" (Borges, 1995b: 89-100) -. En una conferencia expone así sus posibilidades creativas, a partir de un número muy limitado de elementos:

Yo compilé hace tiempo un libro titulado Manual de zoología fantástica, es decir un libro dedicado, no a los animales comunes, sino a los animales fantásticos. Ya que estos anímales se crean por arte combinatorio, ya que en el centauro, por ejemplo, se conjugan el caballo y el hombre; en el minotauro, el hombre y el toro; en el dragón, la serpiente y el pájaro, pensé que el número de animales fantásticos sería virtualmente infinito. Lo busqué en la Historia natural de Plinio, en la Tentación de Flaubert, en diversas mitologías occidentales y orientales. Y comprobé con algún asombro que el jardín zoológico fantástico, digámoslo así, no era más rico que el jardín zoológico real (1967: 5).

De esta manera, excluido el emisor, el protagonismo recae en el mensaje y en el receptor, en el libro y el lector: de la interacción entre ambos derivaría "el hecho estético". Muchos han visto en esta idea de Borges el origen de la estética de la recepción de Jauß o del análisis semiótico de Eco. Pueden apoyarse en numerosos textos:

El libro no es un ente incomunicado: es una relación, es un eje de innumerables relaciones. Una literatura difiere de otra, ulterior o anterior, menos por el texto que por la manera de ser leída (Borges, 1995c: 158).

Un libro es una cosa entre las cosas, un volumen perdido entre los volúmenes que pueblan el indiferente universo, hasta que da con su lector, con el hombre destinado a sus símbolos. Ocurre entonces la emoción singular llamada belleza [...] (2005: 477).

Borges, por su parte, atribuye el descubrimiento a Berkeley:

El sabor de la manzana (declara Berkeley) está en el contacto de la fruta con el paladar, no en la fruta misma; análogamente (diría yo) la poesía está en el comercio del poema con el lector, no en la serie de símbolos que registran las páginas de un libro. Lo esencial es el hecho estético, el thrill, la modificación física que suscita cada lectura (2002c: 11).

Berkeley no cree en los conceptos abstractos ni en la realidad de los objetos externos: la percepción que experimentamos de los mismos es lo único cierto. La idea está, 
de alguna manera, en el texto del filósofo inglés, pero sin duda hace falta un lector de gran agudeza para hacer de ella una teoría estética. Parece haberse inspirado en este pasaje de Alcifrón, o el filósofo minucioso, que insiste sobre la inexistencia de los universales de tipo platónico:

Euphranor: [...] Be pleased then to inform me, what is it we call beauty in the objects of sense?

Alciphron: Every one knows beauty is that which pleases.

Euphranor: There is then beauty in the smell of a rose, or the taste of an apple?

Alciphron: By no means. Beauty is, to speak properly, perceived only by the eye.

Euphranor: It cannot therefore be defined in general-that which pleaseth ?

Alciphron: I grant it cannot (Berkeley, 1901: 132-133).

También Emerson y Heráclito inspiran a Borges esta concepción de la lectura:

Emerson dijo que una biblioteca es un gabinete mágico en el que hay muchos espíritus hechizados. Despiertan cuando los llamamos; mientras no abrimos un libro, ese libro, literalmente, geométricamente, es un volumen, una cosa entre las cosas. Cuando lo abrimos, cuando el libro da con su lector, ocurre el hecho estético. Y aun para el mismo lector el mismo libro cambia, cabe agregar, ya que cambiamos, ya que somos (para volver a mi cita predilecta) el río de Heráclito, quien dijo que el hombre de ayer no es el hombre de hoy y el de hoy no será el de mañana. Cambiamos incesantemente y es dable afirmar que cada lectura de un libro, que cada relectura, cada recuerdo de esa relectura, renuevan el texto. También el texto es el cambiante río de Heráclito (Borges, 2007: 301).

Otra inspiración reivindicada es Whistler:

I read once that the American painter Whistler was in a cafe in Paris, and people were discussing the way in which heredity, the environment, the political state of the times, and so on, influence the artist. And then Whistler said, "Art happens" That is to say, there is something mysterious about art. I would like to take his words in a new sense. I shall say, Art happens every time we read a poem (Borges, 2000: 6).

Esta concepción afecta directamente al objeto de nuestro interés: la visión borgiana del género literario:

Croce creía que no hay géneros; yo creo que sí, que los hay en el sentido de que hay una expectativa en el lector. Si una persona lee un cuento, lo lee de un modo distinto de su modo de leer cuando busca un artículo en una enciclopedia o cuando lee una novela, o cuando lee un poema. Los textos pueden no ser distintos pero cambian según el lector, según la expectativa. Quien lee un cuento sabe o espera leer algo que lo distraiga de su vida cotidiana, que lo haga entrar en 
un mundo no diré fantástico -muy ambiciosa es la palabra- pero sí ligeramente distinto del mundo de las experiencias comunes (VVAA, 1993, 440).

En otro lugar lo formula así:

Pensar es generalizar y necesitamos esos útiles arquetipos platónicos para poder afirmar algo. Entonces, cpor qué no afirmar que hay géneros literarios? Yo agregaría una observación personal: los géneros literarios dependen, quizá, menos de los textos que del modo en que éstos son leídos. El hecho estético requiere la conjunción del lector y del texto y sólo entonces existe. Es absurdo suponer que un volumen sea mucho más que un volumen. Empieza a existir cuando un lector lo abre. Entonces existe el fenómeno estético, que puede parecerse al momento en el cual el libro fue engendrado (Borges, 2005: 204).

Esta idea también le aproxima al concepto que Eco denominará "lector modelo" o al horizonte de expectativas de Jauß: en una conferencia del 78 nos dice que hay un tipo de lector, "el lector de ficciones policiales", que ha sido "engendrado por Edgar Allan Poe". Propone a continuación que imaginemos la lectura desde otro punto de vista; el de un lector posible que es condicionado para leer un texto como si fuera de otro género diferente al acordado habitualmente:

Puede ser un persa, un malayo, un rústico, un niño, una persona a quien le dicen que el Quijote es una novela policial; vamos a suponer que ese hipotético personaje haya leído novelas policiales y empiece a leer el Quijote. Entonces, ¿qué lee? Por ejemplo, si lee: "En un lugar de la Mancha...", desde luego supone que aquello no sucedió en la Mancha. Luego: "...de cuyo nombre no quiero acordarme...", cpor qué no quiso acordarse Cervantes? Porque sin duda Cervantes era el asesino, el culpable. Luego "...no hace mucho tiempo..." posiblemente lo que suceda no será tan aterrador como el futuro (Borges, 2005: 205).

Se trata de un ejercicio no muy diferente del que realiza en "Pierre Menard autor del Quijote" (Borges, 1995b: 47-59): empezamos diciendo que la ambigüedad genérica es una constante en la obra creativa de este autor, pero para ilustrar la práctica de este punto en particular quizá el ejemplo más evidente sea "Un teólogo en la muerte" (Borges, 1998: 107-109). Borges presenta el texto al lector como un cuento fantástico y como tal se deja leer: al final, en el pie de página, descubre que originalmente se trataba de un fragmento teológico de Emanuel Swedenborg.

\section{Conclusión}

Ahora que los ejemplos citados nos han dado elementos de respuesta, podemos volver sobre los tres problemas que habíamos mencionado en la introducción: la 
pertinencia de considerar a Borges como crítico, la posible falacia del Borges precursor y dificultad en delimitar el ámbito crítico borgiano.

Recordemos los dos problemas aducidos por parte de la crítica que niega o limita la legitimidad de Borges como crítico: su carácter asistemático y misceláneo por un lado y, en segundo lugar, la supuesta prevalencia de sus intereses como autor, que le vedarían el rigor y objetividad.

El problema del método es nuclear en filosofía de la ciencia y especialmente arduo en las humanas -en gran medida especulativas y que no han conseguido una disciplina tan rigurosa como las naturales-. Naturalmente, no es un problema que podamos abordar aquí, pero valga un ejemplo de cómo, quizá precisamente a causa de ese carácter especulativo, resulta difícil defender el mayor o menor rigor metodológico de un crítico, en nuestro caso, Borges.

Uno de los rasgos considerados como arbitrarios en Borges es su elección de ejemplos, como menciona Monegal en "Borges: una teoría de la literatura fantástica" (1976). En cambio, es precisamente esa misma costumbre, esas aparentemente caóticas series de ejemplos, uno de los valores principales de la crítica borgiana para Genette. Para el estructuralista, con esa elección aparentemente arbitraria Borges declara y pone en práctica una visión «panteísta» y sincrónica de la literatura -relacionada directamente con el desprecio del tiempo y de la individualidad del autor que hemos mencionado- que podría ser sensible a elementos que pasan desapercibidos a otros enfoques:

Depuis plus d'un siècle, notre pensée -et notre usage- de la littérature sont affectés par un préjugé dont l'application toujours plus subtile et plus audacieuse n'a cesé d'enrichir, mais aussi de pervertir et finalement d'appauvrir le commerce des Lettres : le postulat selon lequel une oeuvre es essentiellement déterminée par son auteur, et par conséquent l'exprime. Cette redoutable évidence n'a pas seulement modifié les méthodes et jusqu'aux objets de la critique littéraire, elle retentit sur l'opération la plus délicate et la plus importante des toutes celles qui contribuent à la naissance d'un livre: la lecture (Genette, 1996: 123-132).

El segundo punto, la supuesta prevalencia de sus intereses como autor, es menos defendible. Es arriesgado juzgar a cualquier autor, crítico o creativo, basándose en intenciones no declaradas, secretas o inconscientes, ya que se podría caer fácilmente en meras especulaciones; pero en caso de que, efectivamente, la tarea crítica de Borges estuviera al servicio de su obra creativa, eso no la hace más o menos rigurosa que la de cualquier otro crítico. Lo que sí nos permite juzgar esta doble faceta es la coherencia entre ellas. Por ejemplo: si cuando vimos más arriba los temas posibles del relato fantástico lo limitado de la lista llama la atención y desafía al lector a buscar contraejemplos, sería muy sencillo aplicar el esquema a la obra de Borges, en la que encaja con exactitud. 
Los ejemplos que hemos visto hasta aquí, que reflejan una persistente coherencia de su pensamiento poético a lo largo de los años, el hecho de que alguna de las categorías que postuló o esbozó sigan siendo operativas como herramientas críticas, así como que sea reivindicado como referente por críticos posteriores, son, sin duda, elementos que han llevado a autores más recientes a rebatir las suspicacias sobre el valor académico de esta faceta borgiana.

En el más modesto de los casos, si aceptamos los recelos más conservadores, se podría considerar al Borges crítico como una suerte de autoconciencia de su obra creativa.

En lo relativo a la pertinencia de considerar a este autor como precursor, si bien su legado es inmenso y la influencia que se le atribuye sin duda legítima, pero asumirla irreflexivamente puede provocar las dificultades que hemos enunciado en la introducción; una forma de cautela sería observar el contexto.

Ya hemos mencionado aquí algunos hallazgos de Borges en relación con otros similares de sus contemporáneos: la visión de los cuentos de hadas como estructuras férreas, las reglas del relato policial, etc. Otra coincidencia curiosa que podemos mencionar sería la aparición de ensayos de ficción como "The Endochronic Properties of Resublimated Thiotimoline" de Asimov (1948: 120-125), sólo nueve años después de "Pierre Menard, autor del Quijote" (Borges, 1995b: 47-76), o, unos decenios antes, "Studies in theLiterature of Sherlock Holmes" (1928), de Roland Knox, que inaugura todo un género donde el ensayista finge creer que Holmes es un personaje real. Pero no hay que olvidar un elemento fundamental que hemos mencionado hace un instante: la escritura de Borges como ejercicio autoconsciente.

Una de las características fundamentales que acerca el Borges ensayista al narrador, más allá de las ambigüedades formales, es el siguiente tema: toda su escritura gira en torno a la escritura misma. Es este uno de los rasgos fundamentales y definitorios de las vanguardias del siglo XX. El tema principal del arte y de la literatura de vanguardia es la reflexión sobre el propio medio de expresión, a menudo desde el propio medio, otras desde el ensayo. Por eso no es de extrañar que haya tantos artistas que ejercían también como ensayistas de esta época, con mayor o menor fortuna: Breton, Dalí, Kandinsky, Cocteau, etc. ¿Qué eran los manifiestos de los distintos «ismos» sino ensayos? Es decir, una de las características centrales y que definen la escritura de Borges le hacen afín a las vanguardias, por supuesto, incluso mucho después de que renegara del ultraísmo.

Por otro lado, analizar sus fuentes de inspiración y antecedentes nos ayudan a calibrar el alcance de su originalidad.

Un ejemplo válido para aplicar estas dos precauciones nos lo da la afirmación, ya tópica, de que ciertas fantasías de Borges -la Biblioteca de Babel, el Aleph, etc.- prefiguran internet. En realidad, los que esto afirman, se basan en la idea, recurrente en Borges, de la 
creación por combinación aleatoria exhaustiva: él mismo nos ofrece una erudita relación de los precedentes de la idea, desde los más remotos, en su ensayo "La biblioteca total" (1999a: 24-27): Demócrito, Aristóteles, Leucipo, pasando por Raimundo Lulio, y muchos de sus autores favoritos como Lewis Carol o Jonathan Swift- hasta llegar al precedente inmediato, "La biblioteca universal", relato de Kurd La Bwitz publicado en 1904.

Las ideas de creación por mera combinatoria fueron formalizadas por matemáticos en la misma época en la que Borges especulaba sobre ellas. El llamado teorema del mono infinito -que retoma la idea de que un mono combinando letras aleatoriamente podría reescribir a Shakespeare en un periodo de tiempo lo suficientemente largo (o toda la biblioteca del Museo Británico, en la versión recogida por Borges)- fue enunciado formalmente por el matemático francés Émile Borel en 1909. Este teorema es una instancia de la ley cero-uno, formalizada por Andréi Kolmogórov en los años 30.

Un ejemplo de cómo esta idea se fue desarrollando posteriormente en la creación literaria: Gianni Rodari (2001) propuso utilizar aleatoriamente las funciones de Propp para crear cuentos en 1973: actualmente se encuentran en el mercado juegos de cartas y dados que retoman esta idea.

Para terminar, volvamos sobre la dificultad de delimitar el ámbito crítico borgiano. Es en ésta donde estriba el interés de Borges como crítico. Nos recuerda en "De las alegorías a las novelas":

Observa Coleridge que todos los hombres nacen aristotélicos o platónicos. Los últimos intuyen que las ideas son realidades; los primeros, que son generalizaciones; para éstos, el lenguaje no es otra cosa que un sistema de símbolos arbitrarios; para aquéllos, es el mapa del universo. El platónico sabe que el universo es de algún modo un cosmos, un orden; ese orden, para el aristotélico, puede ser un error o una ficción de nuestro conocimiento parcial (1995c: 155).

Continúa el texto con una nómina de nombres famosos que se inscribirían en una u otra tradición:

A través de las latitudes y de las épocas, los dos antagonistas inmortales cambian de dialecto y de nombre: uno es Parménides, Platón, Spinoza, Kant, Francis Bradley; el otro, Heráclito, Aristóteles, Locke, Hume, William James. En las arduas escuelas de la Edad Media todos invocan a Aristóteles, maestro de la humana razón (Convivio, IV, 2), pero los nominalistas son Aristóteles; los realistas, Platón.

Borges lo haría, evidentemente, en la de los nominalistas. El lenguaje es una búsqueda parcial y una herramienta imperfecta, un código que no tiene, como pensaban los cabalistas, un nexo directo con el cosmos, sino que, como las categorías del lenguaje analítico de John 
Wilkins, son convencionales. Es un escepticismo profundo, similar al que atribuye a la herejía de "La lotería de Babilonia" (Borges, 1995b: 71-80), que "razona que es indiferente afirmar o negar la realidad de la tenebrosa corporación [la que supuestamente gestionaba la lotería] porque Babilonia no es otra cosa que un infinito juego de azares".

Cuando Borges nos dice cómo Pascal "sintió vértigo, miedo y soledad" ante el universo enorme y effroyable habla de sí mismo (Borges, 1995c: 13-16 y 98-101). La desesperanza solo se modera por la posibilidad de no ser nadie, una disolución del yo que es equivalente a ser todos. Cita esta frase de Emerson:

Nuestro destino es trágico porque somos, irreparablemente, individuos, coartados por el tiempo y por el espacio; nada, por consiguiente, hay más lisonjero que una fe que elimina las circunstancias y que declara que todo hombre es todos los hombres y que no hay nadie que no sea el universo.

Esta reflexión, próxima al panteísmo y al budismo está en la raíz misma de la concepción de la literatura de Borges. El yo pasa, pero tenemos, incluso si no es gran cosa o puede ser un error, el juego de las palabras que van, vienen y, de alguna manera, nos unen.

La obra de Borges es una reflexión sobre los actos de escritura y lectura, es decir, la experimentación con un código arbitrario, quizá erróneo, convencional en el mejor de los casos. Se ha subrayado a menudo el componente lúdico de la literatura borgiana, pero si se trata de un juego, se trata de uno que es también y sobre todo, un método de conocimiento. Si Borges defiende, frente a Croze, la existencia de los géneros literarios, es porque representan una herramienta epistemológica: "La literatura fantástica no es una evasión de la realidad, sino que nos ayuda a comprenderla de un modo más profundo y complejo" (Fernández Ferrer, 1988: 166).

La teoría literaria de Borges es coherente pero no es un fin en sí misma: es necesario verla en conjunto con sus ideas filosóficas y su obra creativa para apreciar esa coherencia.

De las propuestas precursoras de Borges, más allá de sus puntos en común con la crítica contemporánea, habría que subrayar la lucidez de su expresión, en términos literarios, del paso, a través de los siglos, de un mundo platónico-realista a uno aristotéliconominalista; el espíritu intelectual de finales del siglo XX, muestra como el paso de las alegorías a las novelas que Borges sitúa en Petrarca continúa radicalizándose, desde un mundo de creencias a un mundo analítico y escéptico. Los hallazgos de Borges son pasos en ese sentido. 


\section{Referencias bibliográficas}

Asimov, Isaac. "The Endochronic Properties of Resublimated Thiotimoline". Astounding Science FictionVol 41, 1.marzo (1948): 120-125.

Berkeley, Georges (1901). Alciphron, or The Minute Philosopher, The Third Dialogue, en The Works of George Berkeley, vol. II. Alexander C. Fraser ed. Oxford: Clarendon Press.

BioyCasares, Adolfo."Comentario a "El jardín de los senderos que se bifurcan" de Jorge Luis Borges". Sur 92 (1942): 60-61.

Borges, Jorge Luis (1967). "La literatura fantástica. Conferencia". Buenos Aires: Ediciones culturales Olivetti.

Borges, Jorge Luis (1962). "Prólogo". Hernández, José. El gaucho Martín Fierro. La vuelta de

Martín Fierro. Buenos Aires: Ediciones Centurión.

Borges, Jorge Luis (1990). Textos cautivos: ensayos y reseñas en «El Hogar». Enrique Sacerio-Garí y Emir Rodríguez Monegal eds. Barcelona: Tusquets.

Borges, Jorge Luis (1995a). Discusión. Madrid: Alianza.

Borges, Jorge Luis (1995b). Ficciones. Madrid: Alianza.

Borges, Jorge Luis (1995c). Otras inquisiciones. Madrid: Alianza.

Borges, Jorge Luis (1998). Historia universal de la infamia. Madrid: Alianza.

Borges, Jorge Luis (1999a). Jorge Luis Borges en Sur 1931-1980.Sara del Carril, Luisa y Mercedes Rubio de Socchiedas. Buenos Aires: Emecé.

Borges, Jorge Luis (1999b). "Prólogo" en Adolfo Bioy Casares. La invención de Morel. El gran Serafín. Madrid: Cátedra.

Borges, Jorge Luis (2000). This Craft of Verse. Calin Andrei Mihailescu ed. Harvard University Press.

Borges, Jorge Luis (2002a). Diálogos de Borges y Sabato. Orlando Barone ed. Planeta, Barcelona.

Borges, Jorge Luis (2002b). El Informe de Brodie. Madrid: Alianza Editorial

Borges, Jorge Luis (2002c). Poesía completa, 1. Madrid: Alianza.

Borges, Jorge Luis (2005). Obras completas, 4. Buenos Aires: Emecé.

Borges, Jorge Luis y Osvaldo Ferrari (2005). En diálogo I. México D.F.: Siglo XXI.

Borges, Jorge Luis (2007). Obras completas, 3. Buenos Aires: Emecé.

Borges, Jorge Luis (2011). Miscelánea. Madrid: Alianza. 
Blüher, Karl Alfred. "La crítica literaria en Valérie y Borges". Revista Iberoamericana 135136 (1986): 447-461.

Cuesta Abad, José Manuel (1995). Ficciones de una Crisis: Poética e Interpretación en Borges. Madrid: Gredos.

De Diego, José Luis (1988). "La teoría contemporánea a partir de Borges" Orbistertius 1. La Plata: Centro de Estudios de Teoría y Crítica Literaria: 31-48.

Echavarría, Arturo (2006). Lengua y literatura de Borges. Madrid: Iberoamericana.

Fernández Ferrer, Antonio (1988). Borges A/Z. Madrid: Siruela.

Genette, Gerard (1966). Figures 1. Paris: Seuil.

Gil Guerrero, Herminia (2008). Poética narrativa de Jorge Luis Borges.Madrid: Iberoamericana.

Haycraft, Howard (1941). Murder for Pleasure. New York City: D. Appleton-Century Company.Hildebrant, César (2008). Cambio de Palabras. Iquitos: Tierra nueva.

Knox, Roland. "Studies in the Literature of Sherlock Holmes". Essays in Satire, (1928).

Lafforgue, Jorge Raúl, y Jorge B. Rivera (1996). Asesinos de papel: ensayos sobre la narrativa policial. Buenos Aires: Colihue.

Lida, Raimundo (1981). Letras Hispánicas. México-Buenos Aires: Colegio de México.

Piglia, Ricardo. "Los usos de Borges". Entrevista de Sergio Pastomerlo. Variaciones 3 (1997). Pittsburgh: Borges Center.

Propp, Vladimir (1965 y 1970). Morphologie du conte. París: Seuil.

Rodari, Gianni (2001). Grammatica della fantasia. Turín: Einaudi.

Rodríguez Monegal, Emir. "Borges: una teoría de la literatura fantástica". Revista Iberoamericana 95(1976): 177-189.

Rodríguez Monegal(1992). Narradores de esta América. Montevideo: Alfadil: 210.

VVAA (1993). Del cuento y sus alrededores. Caracas: Monte Ávila. 